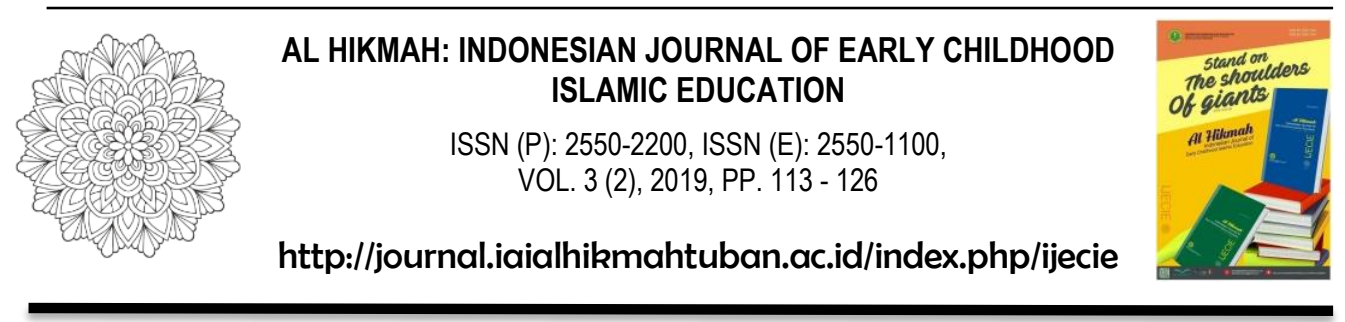

\title{
PENGEMBANGAN PEMBELAJARAN MENGENAL BILANGAN MELALUI TANGGA MANIK-MANIK MONTESSORI DI KELAS A TK ANGGREK KARANGPLOSO MALANG
}

\section{Ari Kusuma Sulyandari}

Prodi Pendidikan Islam Anak Usia Dini, Universitas Islam Malang ari.kusuma@unisma.ac.id

\begin{abstract}
Abstrak
Tujuan dari penelitian ini untuk memudahkan anak-anak memahami bilangan sebelum mengoperasikannya. Penelitian ini menggunakan penelitian pengembangan, yang mengembangkan pembelajaran mengenal bilangan menggunakan manik-manik tangga milik doket Montessori. Teknik pengambilan data menggunakan observasi, wawancara dan dokumentasi berupa vidio dan foto. Hal yang diperhatikan dalam pengembangan ini adalah, keamanan penggunaan media untuk anak-anak, kesenangan dan kemudahan penggunaan medianya.

Kata Kunci: pengembangan, mengenal bilangan, manik-manik montessori

\section{Abstract}

The purpose of research is how children understand numbers. before the children operate it. This research uses development research. researchers develop learning techniques. learning equipment is Montessori's beads. Data collection techniques using observation, interviews and documentation. the matter to be considered in this development is, the safety of the use of media for children, the pleasure and ease of use of the media.
\end{abstract}

Keyword: development, accounting, Montessori's beads 


\section{PENDAHULUAN}

Usia 4-6 tahun merupakan masa peka yang akan terjadi secara spontan dan tidak dapat terulang kembali, masa ini adalah masa-masa penting bagi anak untuk mengembangkan seluruh aspek perkembangannya secara seimbang, karena menurut pendapat Kartini (2013: 26), bahwa usia TK adalah usia golden age karena seluruh aspek perkembangannya telah siap untuk dikembangkan, maka dari itu menstimulus seluruh aspek perkembangan pada anak TK dirasa tepat. Hal ini sejalan dengan pendapat Montesori (2013: 78), bahwa perkembangan anak tahap awal dibagi menjadi dua yaitu usia lahir sampai 3 tahun dan usia 3 tahun sampai 6 tahun, sedangkan usia TK adalah usia 4-6 tahun. Montesori menyebut usia TK dengan periode-periode sensitif dan periode otak menyerap, karena anak dapat menerima stimulus dari luar (lingkungan) yang bersifat terarah untuk membangun kemandirian anak. Periode-periode sensitif ini akan berpengaruh pada pendidikan selanjutnya. Periode sensitif adalah masa dimana perkembangan anak telah siap untuk dikembangkan dan harus distimulus secara seimbang. Dari beberapa pendapat di atas, maka penting bagi anak untuk mendapatkan pendidikan agar siap memasuki jenjang berikutnya.

Masalah yang timbul di pendidikan TK adalah anggapan masyarakat bahwa sekolah TK adalah sekolah membaca, menulis dan berhitung, sehingga Guru lebih menitik beratkan pembelajaran pada membaca, menulis dan berhitung. Berhitung adalah hal yang erat dengan matematika, hal ini diungkapkan oleh Gordon (2011: 295) yang menyatakan bahwa matematika erat hubungannya dengan kognitif anak yang berarti belajar kecakapan mengingat dan berpikir abstrak. Belajar matematika berarti belajar angka. Mengenal angka adalah mengenal banyak benda yang kemudian disimbolkan dengan bilangan, sehingga arah berpikir anak dituntun ke arah yang abstrak. Menurut Sulyandari (2016: 69) pembelajaran mengenal bilangan seharusnya 
melalu tahap mengenal banyak benda terlebih dahulu kemudian mengenalkan bilangan, namun menurut observasi awal di beberapa TK Karangploso, banyak guru yang langsung mengenalkan bilangan pada anak, sehinga anak mengalami kesulitan dalam mengenal bilangan terlebih jika dioperasikam misalnya $1+1=\ldots$

Berdasarkan paparan di atas, penulis mengembangkan pembelajaran mengenal bilangan melalui tangga manik-manik yang telah diterapkan oleh dokter Montessori, dengan harapan dapat memudahkan anak dalam mengenal bilangan, ketika anak sudah mengenal bilangan dengan benar dan tidak hanya sekedar meniru simbol-simbol bilangan, mereka akan mudah untuk mengoperasikan bilangan karena konsep bilangan lebih diperlukan dari pada hanya mengenal simbol bilangan tanpa tahu maknanya.

\section{Pembelajaran Mengenal Bilangan}

Baroody (1989: 50) berpendapat bahwa pada umumnya perkembangan matematika pada anak berawal dari rasa ingin tahu yang akhirnya meluas ke pengetahuan umum. Pegetahuan umum juga meliputi bilangan, karena bilangan ada pada kehidupan sehari-hari misalnya transaksi sehari-hari menggunakan uang yang tertera angka. Wolfinger (1994: 12) berpendapat, bahwa matematika meliputi tiga area pada pembelajaran anak TK yaitu, pencarian, pemecahan masalah dan penghitungan. Dari pendapat tersebut dapat dijabarkan bahwa sebelum anak-anak menguasai berhitung, mereka harus belajar untuk mengenal bilangan dengan cara mencari dan memecahkan masalah, maka dari itu pemahaman anak-anak tentang bilangan pasti berbeda dengan orang dewasa.

Bilangan adalah kumpulan dari angka yang dapat dioperasikan, sehingga bilangan 10 terdiri dari angka 1 dan 0 . Pembelajaran mengenal bilangan asli 1 sampai 10 memungkinkan dilakukan di TK karena seluruh 
aspek perkembangan anak sudah matang, hal ini dikuatkan oleh pendapat Kartini (2013: 26), yang menyatakan bahwa usia TK adalah usia golden age (usia emas) karena seluruh aspek perkembangannya telah siap untuk dikembangkan dengan berbagai stimulus kegiatan. Pembelajaran dilakukan harus melalui bermain, karena Menurut Baroody (1987: 51), yang terpenting dari teori kognitif adalah menjelaskan bagaimana anak-anak paham tentang matematika, sehingga anak-anak memahaminya dengan bertahap dan tidak bisa dipelajari dengan pasif.

Pembelajaran mengenal bilangan dengan tujuan menstimulus kognitif anak usia TK banyak yang dilakukan dengan cara pasif. Pembelajaran yang dilakukan guru tidak berpusat pad anak. Anak secara pasif memperoleh pengetahuan sehingga mengurangi nuansa bermain, padahal pembelajaran kognitif dapat distimulus dengan aktif mengingat usia TK adalah usia bermain. Seperti halnya pendapat Gery (1989), Guru dapat memberikan wawasan untuk memahamkan konsep matematika contoh: pasar-pasaran akan memudahkan anak untuk belajar penomoran, sedangkan menurut Kamli (1986), kunci dari pemahaman matematika adalah mendorong apa yang mereka lakukan. Dalam perkembangan kognitif anak, tidaklah terlepas dari perkembangan yang lain. Ada beberapa perkembangan yang secara tidak langsung akan berhubungan dan saling berpengaruh salah satunya adalah kemampuan fisik, bagaimana anak-anak belajar tentang bahasa tubuh.

Dari pendapat tersebut, dapat disimpulkan bahwa pembelajaran di TK jarus dilakukan dengan bermain dan tematik terpadu, sehingga pada saat anak mengenal bilangan dengan cara bermain, maka mereka tidak hanya belajar tentang bilangan saja melainkan aspek perkembangan lain akan ikut terstimulus. 


\section{Tangga Manik-manik Montessori}

Tangga manik-manik adalah permainan mengenal konsep banyak benda mulai dari 1 hingga 10 dengan warna berbeda. Tidak hanya itu, dengan tangga manik-manik yang diciptakan oleh dokter Montessori juga mempelajari tentang konsep tinggi rendah serta urutan bilangan yang menjadi pondasi sebelum anak mengenal simbol-simbol angka. Media pemelajaran ini juga dikembangkan oleh Beaty (2010) yang mengembangkan tentang stimulus perkembangan kognitif pada anak menjadi beberapa antara lain: (a) bangun ruang, (b) warna, (c) ukuran, (d) urutan pola, (d) bilangan. Dengan begitu metode pengembangan pembelajaran mengenal bilangan melalui tangga manik-manik dapat di lakukan di TK karena sesuai dengan perkembangan anak dan melalui bermain.

Pengembangan pembelajaran mengenal bilangan melalui tangga manik-manik adalah hal dasar yang harus dipelajari anak sebelum mengenal bilangan, karena hal-hal dasar adalah hal penentu ke pembelajaran tingkat selanjutnya. Hal ini dikuatkan oleh pendapat Montesori (2013: 78), bahwa usia TK adalah periode-periode sensitif dan periode otak menyerap, karena anak dapat menerima stimulus dari luar (lingkungan) yang bersifat terarah untuk membangun kemandirian anak. Periode-periode sensitif ini akan berpengaruh pada pendidikan selanjutnya. Periode sensitif adalah masa dimana perkembangan anak telah siap untuk dikembangkan dan harus distimulus secara seimbang.

Pada pembelajaran manik-manik tangga ini anak diminta untuk mengurutkan dari manik-manik yang paling pendek ke arah yang paling panjang. Paling pendek diisi oleh satu manik-manik dan yang paling panjang diisi oleh sepuluh manik-manik. Satu deret manik-manik memiliki warna yang berbeda, sehingga jika anak belum memiliki kemampuan untuk 
menghitung banyak manik-manik, maka ia akan mengurutkan sesuai ukuran dibantu dengan mengenal warna.

\section{METODE}

Pelaksanaan pengembangan pembelajaran mengenal bilangan, peneliti menggunakan model penelitian dan pengembangan (research and development) dari Borg and Gall (1983:775) yang menggunakan sepuluh langkah, namun prosedur yang dikemukakan di atas tentu saja bukan merupakan langkah-langkah yang harus diikuti secara kaku. Menurut Ardhana (2002: 9) setiap pengembang tentu saja dapat memilih dan menentukan langkah-langkah yang paling tepat bagi dirinya berdasarkan kondisi khusus yang dihadapinya dalam proses pengembangan. Peneliti juga dapat melakukan modifikasi dari langkah-langkah yang dikenalnya berdasarkan pertimbangan-pertimbangan yang terbaik. Langkah pengembangan terdiri dari (1) Research and information collecting-Includes review of literature, classroom observations, and preparation of report of state of the art, (2) planning-Incuding defining skills, stating objective determining course sequence, and small scale feasibility testing, (3) develop preliminary form of product-Includes preparation of instruction materials, handbooks, and evaluation devices, (4) preliminary field testing-Conductedin from 1 to 3 schools, using 6 to 12 subjects. Interview, observational, and questionnaire data collected and analyzed, (5) Main product revision - Revision of product as suggested by the prelymnary field-test result, (6) Main field testingConducted in 5 to 15 schools with 30 to 100 subjects. Quantitative data on subjects precourse and postcourse performance are collected. Results are evaluated with respect to course objective and are compared with control group data, when appropriate, (7) operational product revision-revision of product as suggested by main field-test results. 
Pengembangan pembelajaran mengenal bilangan memodifikasi langkahlangkah tersebut menjadi tujuh langkah, yaitu: (1) Melakukan penelitian dan pengumpulan informasi (kajian pustaka, pengamatan kelas, persiapan laporan pokok persoalan). (2) Melakukan perencanaan berupa penyusunan rancangan kegiatan pada sirkuit yang selanjutnya dievaluasi oleh para ahli. (3) Mengembangkan bentuk produk awal berupa lintasan sirkuit setelah dievaluasi oleh para ahli pembelajaran anak usia dini. (4) Melakukan uji coba lapangan (uji coba kelompok kecil) terhadap 6 anak kelompok A. (5) Melakukan revisi terhadap produk awal berdasarkan hasil uji coba lapangan permulaan (uji coba kelompok kecil) utama (sesuai dengan saran-saran dari hasil uji lapangan permulaan). (6) Melakukan uji coba lapangan utama dengan 35 subyek. (7) Melakukan revisi produk (berdasarkan saran-saran dari hasil uji lapangan utama).

Subyek peneliti yang terlibat dalam pengambilan data adalah, (1) Observasi untuk kebutuhan prariset dilakukan terhadap guru serta anak-anak kelompok A TK Anggrek (2) Subyek evaluasi terdiri dari dua hal pembelajaran anak di TK. (3) Subyek uji coba kelompok kecil diambil dari anak kelas A sebanyak 6 anak. (4) Subyek uji coba lapangan (kelompok besar) menggunakan anak kelas A sebanyak 35 anak.

Jenis data yang diperoleh merupakan data kualitatif dan kuantitatif. Data kualitatif diperoleh dari hasil tinjauan para ahli berupa saran dan masukan serta hasil wawancara pada penelitian awal terhadap guru kelas A. Data kuantitatif diperoleh dari data uji coba kelompok kecil dan kelompok besar melalui angket dan observasi pada saat kegiatan berlangsung. Yang diamati adalah kemudahan untuk melakukan, kesenangan anak pada saat melakukan serta aktivitasnya tidak membahayakan bagi anak. 
Instrumen pengumpulan data yang digunakan dalam penelitian ini dengan menggunakan pendekatan kualitatif dan kuantitatif yang berupa kuisioner (angket), wawancara, dokumentasi dan observasi. Kuesioner digunakan untuk mengumpulkan data kualitatif antara lain: (1) penelitian awal (prariset), (2) peni-laian tanggapan dari guru kelompok A (3) evaluasi dari ahli tentang pengembang-an pembelajaran mengenal bilangan, (4) hasil evaluasi dari para ahli berupa saran dan masukan. Data kuantitatif diperoleh dari uji coba kelompok kecil dan uji kelompok besar. Teknik analisis data yang digunakan dalam penelitian ini menggunakan analisis SWOT yang diperoleh dari uji coba kelompok kecil dan kelompok besar terhadap produk adalah data kuantitatif berupa prosentase tanggapan para ahli terhadap rancangan produk yang dikembangkan dan kemudahan, kesenangan, serta keamanan anak saat melakukan aktivitas pembelajaran pada anak. Data kualitatif berupa saran dan masukan dari para ahli yang digunakan untuk melakukan revisi terhadap rancangan produk yang dikembangkan.

\section{Tabel 1 Deskriptif Presentase}

\begin{tabular}{lll}
\hline Presentase & Keterangan & Makna \\
\hline $76 \%-100 \%$ & Baik & Digunakan \\
\hline $56 \%-75 \%$ & Cukup & Diperbaiki \\
\hline $40 \%-55 \%$ & Kurang Baik & Tidak digunakan \\
\hline$<40 \%$ & Tidak Baik & Tidak digunakan \\
\hline
\end{tabular}

\section{HASIL DAN PEMBAHASAN}

Hasil prariset diperoleh temuan bahwa (1) Guru melakukan pembelajaran mengenal bilangan setelah pembelajaran aktif satu minggu. (2) media yang digunakan adalah buku dan pensil, anak-anak diminta untuk menirukan garis 
yang membentuk bilangan. (3) Guru tidak mengenalkan banyak benda terlebih dahulu. (4) Metode belajar mengenal bilangan diawali dengan mengenalkan bilangan terlebih dahulu, melakukan nyanyian angka, membilang satu sampai sepuluh, menuru angka di papan tulis atau di buku kemudian mengenalkan banyak benda dengan bilangan. (5) dengan metode tersebut, beberapa anak kesulitan menghitung banyak benda karena saat membilang tidak sama dengan benda yang ditujuk.

Dari hasil wawancara yang dilakukan pada guru diperoleh data sebagai berikut; Guru mengenalkan pembelajaran dengan membilang dan atau menyanyi karena dirasa mudah dilakukan oleh anak. Maka dari itu pengembangan pembelajaran mengenal bilangan melalui manik-manik tangga dirasa perlu dilakukan di TK tersebut.

Langkah-langkah pengembangan pembelajaran mengenal bilangan adalah sebagai berikut: (1) guru menyanyikan lagi yang berhubungan dengan bilangan, (2) guru membagi manik-manik dan meminta anak-anak untuk mengurutkan sesuai dengan panjangnya, (3) guru meminta anak-anak untuk menghitung tiap baris manik-manik, (4) guru memberi kartu bilangan di sebelah manik-manik, agar anak mengerti simbol bilangan.

Data uji coba kelompok kecil terhadap produk awal ini dengan 6 anak yang menjadi subyek coba akan dipaparkan sebagai berikut:

\section{Tabel 2 hasil uji coba kelompok kecil terkait dengan aspek kemudahan}

\begin{tabular}{lllc}
\hline \multirow{2}{*}{ No } & Aspek yang dinilai & $\begin{array}{l}\text { Data } \\
\text { diperoleh }\end{array}$ & yang \\
\cline { 3 - 4 } & & Mudah & Sulit \\
\hline 1 & $\begin{array}{l}\text { Kemudahan anak dalam mengurutkan } \\
\text { benda (membedakan panjang dan pendek) }\end{array}$ & $87 \%$ & $13 \%$ \\
\hline 2 & $\begin{array}{l}\text { Kemudahan anak pada mengenal warna } \\
\text { (warna berbeda pada manik-manik) }\end{array}$ & $90 \%$ & $10 \%$ \\
\hline
\end{tabular}


Ari Kusuma Sulyandari (Pengembangan Pembelajaran Mengenal Bilangan)

\begin{tabular}{llll}
\hline 3 & $\begin{array}{l}\text { Kemudahan anak pada saat menghitung } \\
\text { manik-manik }\end{array}$ & $98 \%$ & $2 \%$ \\
\hline Rata-rata & $\mathbf{9 1 , 6 \%}$ & $\mathbf{8 , 3 \%}$ \\
\hline
\end{tabular}

Tabel 3 hasil uji coba kelompok kecil terkait dengan aspek kesenangan

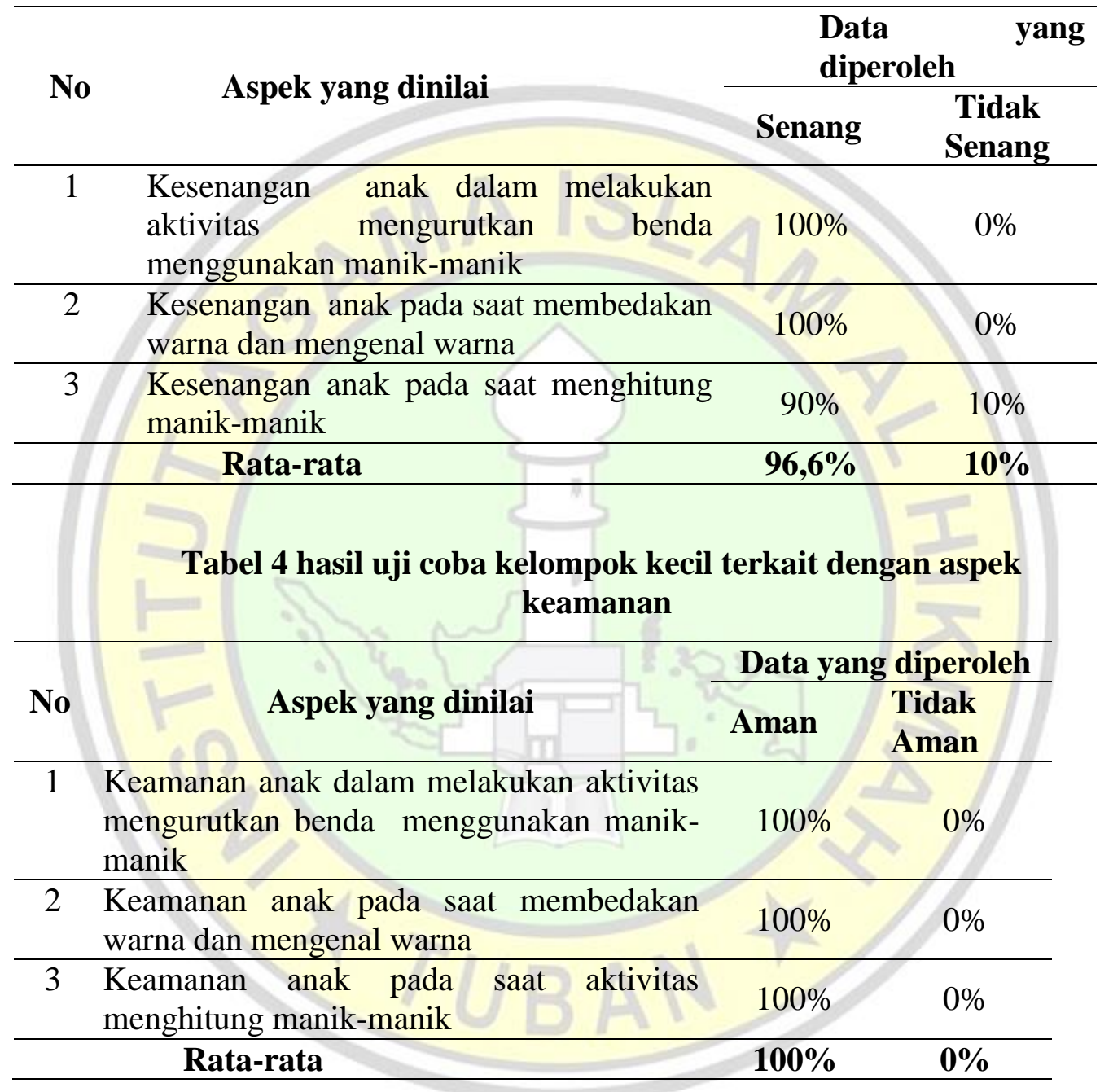

Adapun hasil observasi melalui pengisian angket berupa saran-saran oleh para ahli adalah: (1) Guru seharusnya memulai aktivitas dengan berdoa, agar mengembangkan aspek nilai moral agama. (2) Guru membimbing anak disetiap kegiatan guna memahamkan anak-anak tentang konsep banyak benda 
sebelum mengenal bilangan. (3) Guru harus lebih melakukan interaksi, tanya jawab tentang pada anak untuk stimulus berpikir anak.

Data uji coba kelompok besar pengembangan pembelajaran mengenal bilangan menggunakan subyek sebanyak 35 anak yang diperoleh dari observasi selama proses kegiatan, terkait dengan aspek kemudahan, kesenangan dan keamanan anak dalam melakukan aktivitas tersebut. Pengisian data melalui observasi dilakukan oleh satu orang guru dan peneliti. Adapun data uji coba kelompok besar tersaji dalam tabel berikut:

Tabel 5 hasil uji coba kelompok besar terkait dengan aspek kemudahan

\begin{tabular}{llcc}
\hline \multirow{2}{*}{ No } & Aspek yang dinilai & \multicolumn{2}{c}{$\begin{array}{c}\text { Data yang } \\
\text { diperoleh }\end{array}$} \\
\cline { 3 - 4 } & & $\begin{array}{l}\text { Mudah } \\
\text { Kemudahan anak dalam mengurutkan benda }\end{array}$ \\
\hline 1 & $\begin{array}{l}\text { (membedakan panjang dan pendek) } \\
\text { Kemudahan anak pada mengenal warna }\end{array}$ & $81 \%$ & $19 \%$ \\
\hline 2 & $\begin{array}{l}\text { (warna berbeda pada manik-manik) } \\
\text { (we }\end{array}$ & $90 \%$ & $10 \%$ \\
\hline $\begin{array}{l}\text { Kemudahan anak pada saat menghitung } \\
\text { manik-manik }\end{array}$ & $89 \%$ & $11 \%$ \\
\hline & Rata-rata & $\mathbf{8 6 , 6 \%}$ & $\mathbf{1 3 , 3 \%}$ \\
\hline
\end{tabular}

Tabel 6 hasil uji coba kelompok besar terkait dengan aspek kesenangan

\begin{tabular}{|c|c|c|c|}
\hline \multirow[b]{2}{*}{ No } & \multirow{2}{*}{\begin{tabular}{lll|l|l|} 
Aspek yang dinilai & \\
Kesenanoan anak dalam melakukan
\end{tabular}} & \multicolumn{2}{|c|}{ Data yang diperoleh } \\
\hline & & Senang & $\begin{array}{l}\text { Tidak } \\
\text { Senang }\end{array}$ \\
\hline 1 & $\begin{array}{lrr}\text { Kesenangan anak dalam } & \text { melakukan } \\
\text { aktivitas } & \text { mengurutkan } & \text { benda } \\
\text { menggunakan manik-manik } & \end{array}$ & $100 \%$ & $0 \%$ \\
\hline 2 & $\begin{array}{l}\text { Kesenangan anak pada saat membedakan } \\
\text { warna dan mengenal warna }\end{array}$ & $100 \%$ & $0 \%$ \\
\hline 3 & $\begin{array}{l}\text { Kesenangan anak pada saat menghitung } \\
\text { manik-manik }\end{array}$ & $95 \%$ & $5 \%$ \\
\hline & Rata-rata & $96,6 \%$ & $10 \%$ \\
\hline
\end{tabular}




\section{Tabel 7 hasil uji coba kelompok besar terkait dengan aspek keamanan}

\begin{tabular}{|c|c|c|}
\hline \multirow{2}{*}{ No } & \multirow{2}{*}{ Aspek yang dinilai } & $\begin{array}{l}\text { Data yang } \\
\text { diperoleh }\end{array}$ \\
\hline & & $\begin{array}{ll}\text { Ama } & \text { Tidak } \\
\text { n } & \text { Aman } \\
\end{array}$ \\
\hline 1 & $\begin{array}{l}\text { Keamanan anak dalam melakukan aktivitas } \\
\text { mengurutkan benda menggunakan manik- } \\
\text { manik }\end{array}$ & $\begin{array}{l}100 \\
\%\end{array}$ \\
\hline 2 & $\begin{array}{l}\text { Keamanan anak pada saat membedakan } \\
\text { warna dan mengenal warna }\end{array}$ & $\begin{array}{ll}100 & 0 \\
\% & 0\end{array}$ \\
\hline 3 & $\begin{array}{l}\text { Keamanan anak pada saat aktivitas } \\
\text { menghitung manik-manik }\end{array}$ & $\begin{array}{l}100 \\
\%\end{array}$ \\
\hline & Rata-rata & $\begin{array}{l}100 \\
\%\end{array}$ \\
\hline
\end{tabular}

Revisi setelah uji lapangan (kelompok besar) tidak ada, karena dari hasil analisis terhadap produk awal pembelajaran sudah memenuhi kriteria baik dan dapat digunakan, Setelah melalui langkah-langkah sebagaimana tersebut diatas, maka dinyatakan layak untuk dikembangkan.

Produk pembelajaran mengenal bilangan yang dikembangkan telah dikaji melalui proses yang semestinya hingga menjadi produk akhir, melalui beberapa revisi untuk mendapatkan produk yang maksimal. Uji coba dilakukan melalui langkah-langkah tinjauan dua ahli pembelajaran pendidikan anak usia dini uji coba (kelompok kecil) dan uji lapangan (kelompok besar). Produk pengembangan ini sebagai aktivitas pembelajaran mengenal bilangan memiliki kelebihan-kelebihan yakni: (1) pengembangan pembelajaran mengenal bilangan ini juga mengembangkan lima aspek perkembangan anak yaitu perkebangan bahasa pada saat berinteraksi dengan guru, (2) perkembangan sosial emosional pada saat anak bersabar menghitung banyaknya manik-manik, (3) perkembangan seni pada saat anak mengenal warna, (4) kognitif pada saat anak belajar mengurutkan tangga manik-manik, 
(5) mengenal bilangan dan menghitung manik-manik, (6) nilai-nilai moral dan agama pada saat, guru mengajar siswa untuk berdoa sebelum pelaksanaan. Hal ini sesuai dengan pembelajaran TK yang menggunakan tematik terpadu.

Berdasarkan hasil observasi terhadap proses pembelajaran di atas diperoleh temuan-temuan yaitu (1) pengembangan pembelajaran mengenal bilangan juga mengembangkan aspek lainnya. (2) aktivitas pada pengembangan mengenal bilangan dirasa mudah, menyenangkan dan aman untuk dilakukan anak. (3) anak lebih mudah mengerti konsep bilangan dengan berbagai cara yaitu dengan mengurutkan berdasarkan ukuran panjang-pendek, mengingat berdasarkan warna dan menghitung banyaknya manik-manik. (4) anak tidak hanya mengenal simbol-simbol bilangan 1-10 tetapi dengan tangga manik-manik mereka benar-benar mengerti konsep banyak benda 1-0.

\section{PENUTUP}

\section{Simpulan}

Produk pengembangan pembelajaran mengenal bilangan ini melalui proses yang telah ditentukan mulai dari perancangan produk, uji coba kecil, evaluasi ahli dan uji coba besar hingga mendapatkan produk yang maksimal. Setelah melalui beberapa tahap di atas, didapatkan produk pengembangan pembelajaran mengenal bilangan sebagai berikut:

Berdasarkan kesimpulan tersebut di atas, maka saran yang diajukan adalah Produk penelitian ini pemanfaatannya perlu mempertimbangkan situasi, usia dan tingkat perkembangan anak. Produk yang ditujukan untuk anak paud anggrek kelas A dapat disajikan pada semua anak kecuali anak berkebutuhan khusus, karena tidak dirancang untuk anak tersebut. Produk ini juga dapat digunakan di sekolah lain. Penyebarluasan produk yang dikembangkan kepada sasaran yang lebih luas sebaiknya produk ini dievaluasi 
kembali dan disesuaikan dengan situasi dan kondisi sasaran yang akan dituju. Sebelum disebarluaskan sebaiknya disosialisasikan kepada pihak- pihak terkait untuk memperoleh pengakuan dan perijinan guna penerapan pembelajaran mengenal bilangan.

\section{DAFTAR PUSTAKA}

Ardhana, Wayan. Konsep Penelitian Dalam Bidang Pendidikan danPembelajaran.

Makalah disajikan dalam Loka Karya Nasional Angkatan II Metodologi Penelitian dan Pengembangan Bidang Pendidikan dan Pembelajaran, Jurusan Ilmu Keolahragaan FIP UM, Malang, 22-24 Maret.

Baroody, Athur J dan Jesse L M Wilkinds. (1989). The Development of Informal Counting, Nurmber, and Arithmetic Skills and Consepts. (on-line) (scholar.vt.edu/access/content/user/wilkins/Public/EarlyNumber.pdf), diakses 18 Oktober 2016

Beaty, J.J. (1996). Skills for Preschool Teachers. New Jersey: Prentice-Hall.

Gordon, Ann Miles dan Gordon Williams Browne. (2011). Beginnings and Beyond. Foundations in Early Childhood Education. America: Delmar Publishers inc.

Kartini, Novalia. (2013). Penerapan Model Pembelajaran Numbered of Head Judul Toghether "Kepala Bernomor" untuk Meningkatkan Kemampuan Kognitif Anak Kelompok B di TK ABA 24 Malang. Jurnal Ilmiah PAUD, 1 (1): halaman 26

Montesori, Maria. Tanpa Tahun. Metode Montesori. Terjemah Gutex, Gerald Lee. (2013). Yogyakarta: Pustaka Pelajar.

Musfiroh, Tadkiroatun. (2005). Bercerita Untuk Anak Usia Dini. Jakarta: Depdiknas.

Wolfinger, Donna M. (1994). Science and Mathematics in Early-Childhood Education. America: Harper Collins College Publisher

Sulyandari, Ari Kusuma. (2016). Proses Representasi Simbol Matematika pada Proses Bermain Anak TK. (online), (http://journal.um.ac.id/ index.php/jptpp/article/view/7778 diakses tanggal), 1 November 2019. 